\title{
Behavioural and physiological adaptations of the bearded goby, a key fish species of the extreme environment of the northern Benguela upwelling
}

\author{
Anne G. V. Salvanes ${ }^{1, *}$, Anne C. Utne-Palm ${ }^{1}$, Bronwen Currie ${ }^{2}$, \\ Victoria A. Braithwaite ${ }^{1,3}$ \\ ${ }^{1}$ Department of Biology, University of Bergen, 5020 Bergen, Norway \\ ${ }^{2}$ National Marine Information and Research Centre (NatMIRC), Strand Street Box 912, Swakopmund, Namibia \\ ${ }^{3}$ School of Forest Resources \& Department of Biology, Penn State University, University Park, Pennsylvania 16802, USA
}

\begin{abstract}
Nutrient-rich, upwelling marine areas with high productivity often produce sediments dominated by organic-rich mud. Here, intense decay processes create hypoxic conditions with high concentrations of hydrogen sulphide and methane in the muddy surface layers. Such environments are inhospitable to most forms of life and those organisms that can survive in these areas tend to be specialists that cope with anoxic or hypoxic conditions, e.g. sulphide-oxidising bacteria and chemolithotrophic bacteria. Surprisingly, during recent acoustic and survey work in the northern Benguela region off the coast of Namibia, it was observed that the bearded goby Sufflogobius bibarbatus spends much of the day on the seabed interacting with the hypoxic and sulphidic mud, making a diel vertical migration (DVM) to spend the night in more oxygenated, but jellyfish-rich waters. We describe a series of experiments that demonstrate physiological and behavioural adaptations that enable the gobies to cope with hypoxia, anoxia and exposure to sulphide for prolonged periods of time. We also observed that the fish burrow directly into the muddy substrate when threatened and that, unlike another fish species common to this area, the horse mackerel Trachurus capensis, the gobies tolerate the presence of jellyfish.
\end{abstract}

KEY WORDS: Bearded goby $\cdot$ Behaviour $\cdot$ Physiology $\cdot$ Anoxia $\cdot$ Hypoxia $\cdot$ Sulphide $\cdot$ Benguela Jellyfish

Resale or republication not permitted without written consent of the publisher

\section{INTRODUCTION}

At the end of the Permian period (251 million years ago), more than $95 \%$ of organisms disappeared as the earth experienced a dramatic change in climate; frequent volcanic eruptions led to global warming, a massive decrease in the level of available oxygen and an increase in the levels of hydrogen sulphide (Benton \& Twitchett 2003, Berner 2005, Grice et al. 2005, Lane 2007). During this time, organisms that burrowed into the ground or scavenged in the stagnant mud on ocean shelves were particularly good at coping with hypoxia and hydrogen sulphide, and it was these creatures that managed to survive the Permian mass extinction. Today many organisms are adapted once again to liv- ing in oxygenated environments, but isolated habitats still exist where oxygen levels are low, and here we are discovering animals that have adapted their behaviour and physiology to cope with limited access to oxygen.

One such low oxygen environment is found on the continental shelf off the coast of Namibia. Within this region hypoxic waters and high levels of hydrogen sulphide are a natural consequence of the northern Benguela upwelling ecosystem. This area and other upwelling ecosystems and shallow coastal areas made eutrophic through anthropogenic disturbance and provide current challenging environments for organisms to adapt to (e.g. Zhang et al. 2010).

Very few organisms survive in areas dominated by extreme hypoxic conditions, yet remarkably one spe- 
cies of fish (the bearded goby Sufflogobius bibarbatus) has recently been found within hypoxic areas of the northern Benguela ecosystem (Utne-Palm et al. 2010). The bearded goby is an integral part of the ecosystem, being the major prey fish for large populations of hake Merluccius capensis, horse mackerel Trachurus capensis, penguins, seals and sea birds (Crawford et al. 1987, van der Lingen et al. 2006). In the present study, we examine the kinds of adaptation that allow the goby to survive in an environment with extremely low levels of oxygen and, at times, in the presence of hydrogen sulphide - conditions avoided by most other organisms and certainly all other known vertebrates.

The challenge of surviving in hypoxic environments is common to other nutrient-rich/upwelling areas with high productivity. In the Benguela, the inner shelf area is dominated by organic-rich mud where intense decay processes create hypoxic conditions with high concentrations of hydrogen sulphide and methane in the sediment surface layers (Brüchert et al. 2009). These hypoxic conditions $(<1 \mu \mathrm{M}$ dissolved oxygen, corresponding to $<0.4 \%$ oxygen saturation at $12^{\circ} \mathrm{C}$ ) cover over $9000 \mathrm{~km}^{2}$ and represent $50 \%$ of the shelf area
(Lavik et al. 2009). Approximately $7000 \mathrm{~km}^{2}$ are sulphidic (Schulz et al. 1999), and these can be dominated by both white mats of large sulphide-oxidising bacteria on the seabed (Schulz et al. 1999) and chemolithotrophic bacteria in the water column (Lavik et al. 2009). Diffusion and methane-driven eruptions of hydrogen sulphide gas from the sediment have been involved in massive killing events of fish and invertebrates (Weeks et al. 2002, 2004, Brüchert et al. 2009) as these toxic gases move into and up through the main water column.

Recently, Utne-Palm et al. (2010) reported the capacity for the bearded goby to survive within the hypoxic Benguela sediment surface layers. Their observations indicated that the goby has adaptations that surpass those from any published record for a marine teleost. Their research described how the gobies perform a diel vertical migration (DVM): by day the fish are found on the anoxic seabed, but at night they migrate up into the more oxygenated waters around 40 to $60 \mathrm{~m}$ above the seafloor (Fig. 1). During the night, the gobies move into areas that contain large numbers of jellyfish Chrysaora fulgida and Aequorea forskalea and also

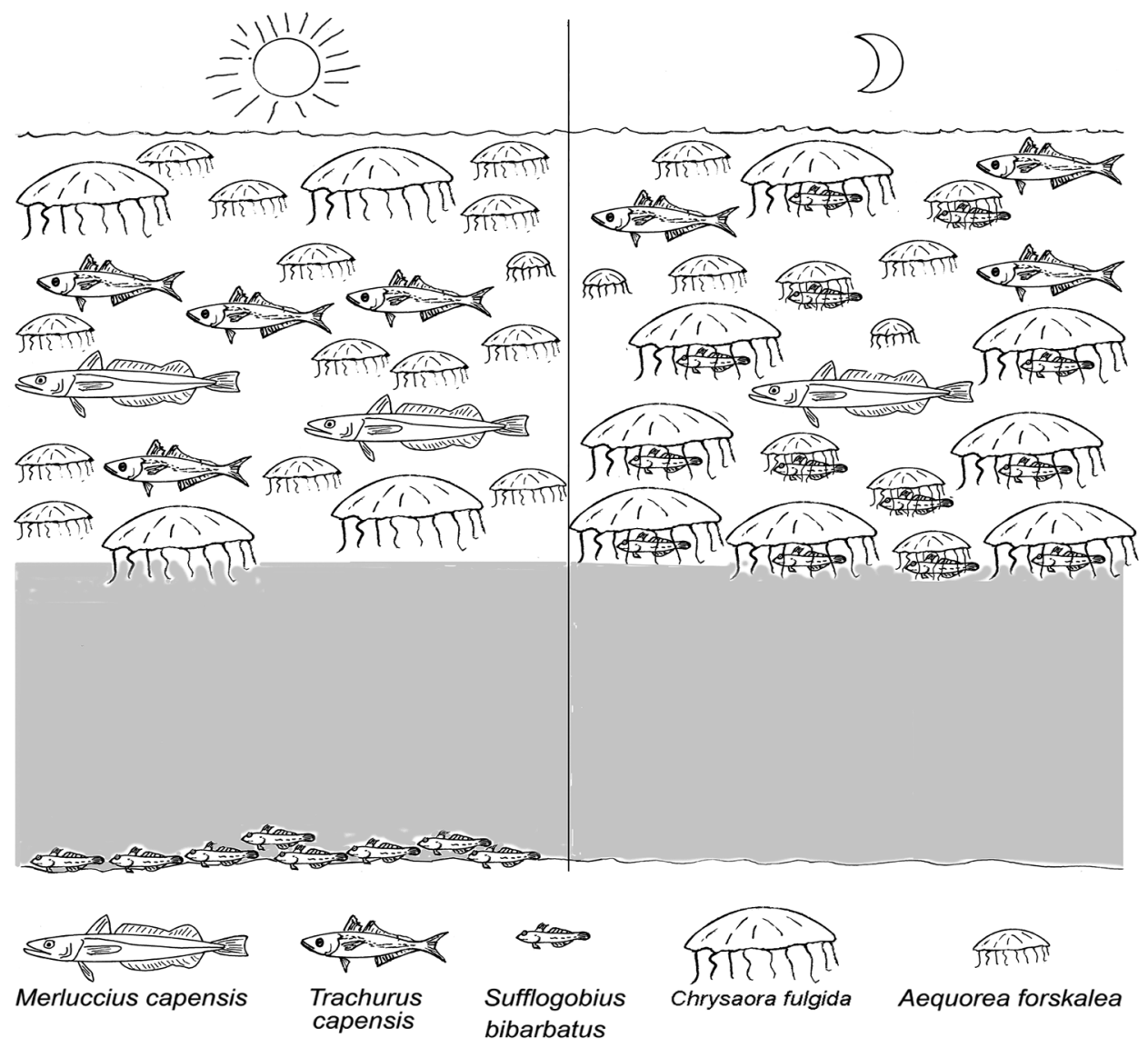

Fig. 1. Vertical distribution pattern of bearded goby Sufflogobius bibarbatus, its main fish predators hake Merluccius capensis and horse mackerel Trachurus capensis, and prey (jellyfish Aequorea forskalea and Chrysaora fulgida) during the day (left) and night (right). Grey shading indicates oxygen saturation below $10 \%$. Figure drawn by Elin Holm 
predators such as Cape hake Merluccius capensis and horse mackerel Trachurus capensis.

To investigate how the bearded goby copes in such an extreme environment, we studied their response to changes in oxygen levels similar to those that they would experience during DVM, and we explored their tolerance of anoxic conditions. We simulated conditions similar to an abrupt eruption of sulphide from the sediment, and then observed how the gobies responded. We also investigated how the gobies interacted with the substrate. Previous work found that gobies preferred to associate with mud rather than sand (Utne Palm et al. 2010); in the present study, however, we explored how and why they interact with the mud. Finally, to investigate the unusual observation that gobies migrate at night into more shallow waters and then associate with jellyfish, we compared the response of gobies and one of their predators (the common pelagic horse mackerel) to the presence of a jellyfish.

\section{MATERIALS AND METHODS}

Over a series of research cruises off the Namibian coast between 2003 and 2008, we ran on board experiments with adult gobies, juvenile horse mackerel and jellyfish. These organisms were caught at depths of less than $105 \mathrm{~m}$ by bottom and pelagic trawl in the Benguela region off Walvis Bay at $23^{\circ} \mathrm{S}, 14^{\circ} \mathrm{E}$. Live fish were removed from the trawl and put into well-aerated seawater in a holding tank $(100 \times 100 \times 40 \mathrm{~cm}) 24 \mathrm{~h}$ prior to the start of experiments. Water was aerated to ca. $80 \%$ of air saturation and cooled to ca. $13^{\circ} \mathrm{C}$, which is the normal bottom water temperature for these fish. Jellyfish were carefully placed in large buckets and kept in frequently changed cooled seawater.

The standard experimental set up that explored the response of fish to changes in oxygen concentration consisted of 6 glass aquaria (Fig. 2; $50 \times 40 \times 30 \mathrm{~cm}$ ). These were painted black on all sides, except the front. Each aquarium was sealed with a Plexiglas roof with a circular opening (ca. $20 \mathrm{~cm}$ diameter) allowing aeration of the water via an air-stone. The aquaria were fitted with 2 cooling coils (ca. $200 \mathrm{~cm}$ ) that contained $4^{\circ} \mathrm{C}$ circulating seawater, which maintained a tank temperature of $13 \pm 1^{\circ} \mathrm{C}$ (Fig. 2). During deoxygenation, the circular opening was sealed with a Plexiglas lid with silicon grease applied around the edges to prevent air from seeping in. An oxygen sensor (type: WTW Oximeter 330i, with probe; WTW Oxi Cal ®-SL) was mounted through a tightly fitted hole in the Plexiglas lid. A stopcock inlet attached to a nitrogen cylinder allowed us to deoxygenate the aquaria water by bubbling nitrogen directly into the tanks, and a tap

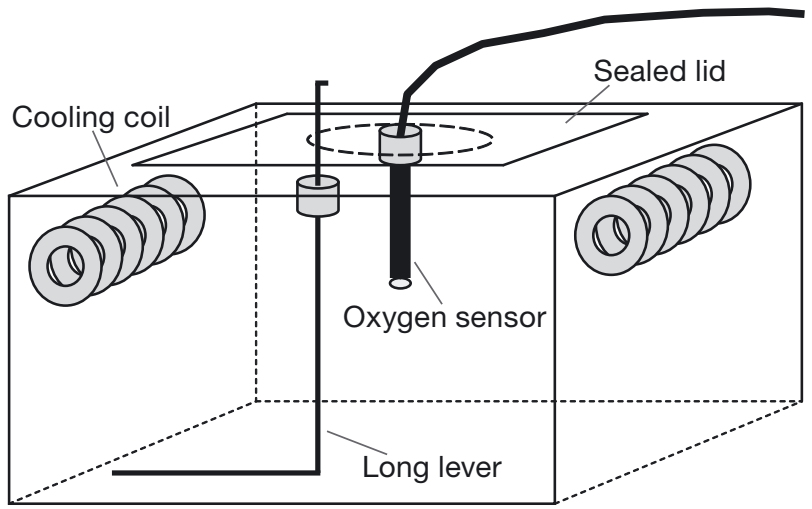

Fig. 2. Experimental aquarium measuring $50 \times 40 \times 30 \mathrm{~cm}$ sealed by a glass roof. The aquarium opening, a circular opening of $20 \mathrm{~cm}$ in diameter in the roof, was closed by a Plexiglas lid $(25 \times 25 \mathrm{~cm})$ during the experiments. Two cooling coils were attached to the Plexiglas lid, to maintain a constant temperature. A long lever was fitted through the lid of the aquarium. This made it possible to rotate it from the outside of the aquarium, to trigger escape response at low oxygen levels. An oxygen sensor was fitted through a hole in the Plexiglas lid

attached to the side of each aquarium allowed us to draw water samples to determine dissolved oxygen (DO). Oxygen is measured as $\mathrm{ml} \mathrm{DO} \mathrm{l}^{-1}$. For comparison with other studies conducted under different temperature conditions using \% saturation, we calculated $\%$ oxygen saturation using the method of Weiss (1970).

All treatments were carried out in accordance with the departmental research ethics board at the University of Bergen, Norway, which is in accordance with national and international regulations of experimenting with animals.

Responses to changes in oxygen concentration associated with DVM. To investigate the response of fish to conditions resembling DVM we tested 35 individuals (mean $\pm \mathrm{SE}$, size $9.5 \pm 0.17 \mathrm{~cm}$; weight $10.5 \pm$ $0.28 \mathrm{~g}$ ) in 8 replicate groups consisting of 4 or 5 adult gobies. The fish were initially acclimated for $2 \mathrm{~h}$ in fully oxygenated water. They then experienced deoxygenation caused by bubbling nitrogen through the aquarium water. This phase continued over $3 \mathrm{~h}$, with the change in DO being measured by the oxygen probe and also by Winkler analysis (Cline 1969) of a water sample collected from the aquarium. Thereafter, a period of reoxygenation began where the lids of the aquaria were opened and air-stones were repositioned in each tank. This phase lasted $1.5 \mathrm{~h}$. Ventilation rate was quantified at different time points: once when the water was fully oxygenated, 5 times during the deoxygenation phase (at $30 \mathrm{~min}$ intervals) and 3 times (at $15 \mathrm{~min}$ intervals) during reoxygenation. 
Effects of prolonged exposure to anoxia. To examine the response of the gobies to prolonged exposure to anoxia, we measured changes in the ventilation rate of a further 15 fish $(11.0 \pm 0.4 \mathrm{~cm})$. Single fish were released randomly into individual experimental aquaria $8 \mathrm{~h}$ prior to the start of a trial. Observations began in fully oxygenated water, followed by 4 to $5 \mathrm{~h}$ deoxygenation, and approximately $4.5 \mathrm{~h}$ of anoxia before 6 of the fish were followed through reoxygenation for ca. $1.5 \mathrm{~h}$. During deoxygenation and reoxygenation the ventilation rate was recorded every $15 \mathrm{~min}$, but when oxygen levels fell below $0.6 \mathrm{ml} \mathrm{l}^{-1}$ the recordings were every $5 \mathrm{~min}$. Seven of the 15 fish that had experienced deoxygenated waters were tested for responsiveness after the $4.5 \mathrm{~h}$ of anoxia (see below). Two of the fish were omitted from analysis because their reoxygenation phase occurred too rapidly.

Measuring the gradual decrease in oxygen level allowed us to estimate the critical oxygen level, $\left[\mathrm{O}_{2}\right]_{\text {crit }}$, for the bearded goby; this is the oxygen level at which the fish shifts from aerobic to anaerobic metabolism (Beamish 1964, Nilsson \& Östlund-Nilsson 2004), and is recognised by a sudden drop in the ventilation rate. The minimum oxygen concentrations were always $<0.12 \%$ air saturation $\left(<0.007 \mathrm{ml} \mathrm{DO} \mathrm{l}^{-1}\right)$ for all fish tested.

Following ca. $4.5 \mathrm{~h}$ exposure to anoxia, 7 fish (11.3 \pm $0.6 \mathrm{~cm}$ ) were used to investigate their responsiveness to tactile stimulation. The fish were touched using a lever attached to the lid of each aquarium (see Fig. 2). The stimulation was repeated 3 times at 5 min intervals. For each event, the time to first response (s) and escape distance $(\mathrm{cm})$ was noted. Afterwards fish were allowed to recover as described above. If a fish lost equilibrium (tipped over on its side) or the opercula beats stopped for more than $150 \mathrm{~s}$ the lid was opened, and an air-stone was added to allow recovery.

Responses to a simulated sulphide eruption. In trials simulating a sulphide eruption, aquarium DO was further reduced by injecting sulphide into the water (the terms 'sulphide' and 'hydrogen sulphide' refer to the total amount of sulphide, $\mathrm{H}_{2} \mathrm{~S}, \mathrm{~S}^{2-}$ and $\mathrm{HS}^{-}$). Seventeen adult gobies were tagged using coloured tags attached to the base of the first dorsal fin. Trials were run with groups of 4 or 5 fish $(9.9 \pm 0.23 \mathrm{~cm}$ and 10.7 $\pm 0.65 \mathrm{~g}$ ). These were initially acclimated to surface seawater temperatures of 16 to $19^{\circ} \mathrm{C}$ and $100 \%$ air saturation (DO level equivalent to surface water) for $2 \mathrm{~h}$ in an aquarium. Each group was then transferred to an experimental aquarium $(50 \times 40 \times 30 \mathrm{~cm})$ at the same temperature, but with an oxygen concentration $<0.017 \mathrm{ml} \mathrm{DO}^{-1}(0.28 \%$ of air saturation) and with sulphide added to give a concentration of approximately $100 \mu \mathrm{mol} \mathrm{l}^{-1}$ total sulphide, conditions similar to those observed during sulphide eruptions. The concentrations of sulphide and oxygen were determined at intervals throughout each experiment by collecting $50 \mathrm{ml}$ water samples for analysis according to the Cline method (Cline 1969), using a portable Merck SQ118 photometer. Exposure to sulphide was therefore reported over the measured range of DO and sulphide concentrations. After $30 \mathrm{~min}$, the fish were transferred back to the fully oxygenated aquaria for recovery. Ventilation rate and whether fish were actively swimming or passive were observed 4 times: in the fully oxygenated water before the exposure, during exposure, and 30 and $90 \mathrm{~min}$ after fish were returned to the fully oxygenated water for recovery.

Testing whether the mud substrate is used as a refuge. Four dark blue plastic tanks $(64 \times 44 \times 45 \mathrm{~cm})$ containing $20 \mathrm{~cm}$ of fresh seawater maintained at ca. $13^{\circ} \mathrm{C}$ were set up in a room held at constant temperature $\left(13^{\circ} \mathrm{C}\right)$. Each tank was centrally divided by a shallow grey plastic wall $(44 \times 2.5 \mathrm{~cm})$ creating 2 halves within each tank. The dividing wall was used to retain mud that had been sampled from the benthic area where the fish were collected on one side; the second side remained empty, with the plastic base of the tank acting as a substrate. To control for possible sideeffects, 2 of the tanks had mud on the right hand side, but the remaining 2 had mud on the left.

One hour before trials began, 20 gobies $(8.6 \pm 1.5 \mathrm{~cm}$; $5.5 \pm 0.3 \mathrm{~g}$ ) were collected from a holding tank on deck and were transferred in black-covered buckets to the constant temperature room. Individual gobies were then caught by dip-net $(10 \times 7 \mathrm{~cm})$ and transferred to the empty side of the blue tank where they were released against the wall furthest from the mud. The fish were observed constantly for the next $2 \mathrm{~min}$, and the time at which they began swimming was noted. If after 2 min the fish remained on the plastic substrate we then moved the dip net around the 3 edges of the non-mud side of the tank, first in a clockwise direction followed by the same movement but in an anticlockwise direction. This general disturbance to the nonmud side of the tank was repeated every $15 \mathrm{~s}$ for a maximum of 5 sweeps, or until the fish swam onto the side containing the mud. Whether the fish entered the side with mud or not, and whether they sat on top of the mud or burrowed themselves in it was noted. At the end of the trials the fish were removed and were weighed and measured.

Goby shelter selection. Twelve new gobies (8.9 \pm $0.1 \mathrm{~cm} ; 6.7 \pm 0.3 \mathrm{~g}$ ) were selected. The same 4 opaque plastic tanks used above were filled with fresh seawater $(20 \mathrm{~cm}$ depth) and were used to investigate whether gobies preferred the soft mud when threatened or whether they used a PVC half-pipe shelter $(5 \mathrm{~cm}$ high, $12 \mathrm{~cm}$ long) that mimicked crevices found on hard, 
rocky substrates typically used as shelters by other goby species. One half of the tank contained a fresh layer of mud while the other half had a plain base with the PVC half-pipe shelter placed against the middle of one of the side walls.

Single fish were released next to the central dividing wall on the solid plastic substrate. Two min after the start of the trial we used the same clockwise and anticlockwise dip net movements as described above to 'threaten' the fish. The dip net sweeps were repeated every $15 \mathrm{~s}$ for a maximum of 8 times. Fish position was noted.

Goby and juvenile horse mackerel interactions with jellyfish. In a controlled temperature room (holding constant $\left.13^{\circ} \mathrm{C}\right), 4$ opaque tanks $(64 \times 44 \times 45 \mathrm{~cm})$ were centrally divided into 2 by a wall of green plastic mesh $(44 \times 45 \mathrm{~cm}$, mesh size: $2.5 \times 2.5 \mathrm{~cm})$. Thirty min before trials began, small groups of gobies and horse mackerel were transferred from a holding tank into 2 of the tanks (keeping the species separate) to allow the fish to adjust to swimming through the mesh. All the fish used in these trials were small enough to swim through the mesh holes. After $30 \mathrm{~min}$, both gobies and horse mackerel were observed crossing the mesh several times, but to ensure each fish had experienced moving between the 2 compartments, the fish were encouraged with a dip net to swim back and forth at least 3 times between the 2 halves of the tank.

The 2 remaining tanks were used as test tanks. Two jellyfish caught on the same day as the experimental trials were kept in buckets of seawater and maintained at ca. $13^{\circ} \mathrm{C}$ until they were transferred into one side of the test tanks. In the first tank, the jellyfish was placed in the left compartment but in the second tank it went into the right compartment. Trials began with a single fish being transferred to a test tank. In half of the trials, fish were placed into the same side as the jellyfish. In the other half, fish were placed into the empty compartment. After $5 \mathrm{~min}$, fish position was noted. A total of 13 juvenile gobies $(8.6 \pm 0.2 \mathrm{~cm} ; 5.8 \pm 0.3 \mathrm{~g})$ and 13 juvenile horse mackerel $(10.2 \pm 0.2 \mathrm{~cm} ; 9.7 \pm 0.5 \mathrm{~g})$ were compared. Gobies and horse mackerel trials were alternated and each species of fish was tested in both test tanks.

Statistical analyses. All statistical analyses were conducted using $\mathrm{R}$ version 2.9.1 (R Development Core Team 2009). The statistical methods described below are explained by Crawley (2007). We applied a Linear Mixed Effects (LME) model to analyse the effect of oxygen level on the ventilation rate. We ran separate analyses for the data from the experiments simulating DVM (change in oxygen level) and the sulphide eruption (change in oxygen and sulphide levels). Repeated observations on the same individual fish or fish that were tested in groups were accounted for by specify- ing Fish and Group as random variables in the models. We also specified the correlation structure corAR1() in the model when this improved the fit to the data. Size had no effect and was therefore removed from the models.

The scatter plot of ventilation rate versus oxygen concentration (representing the experiment testing effect of prolonged anoxia) was very skewed. We therefore used the non-parametric locally weighted scatter-plot smoothing (lowess function of $\mathrm{R}$ ) to fit a curve through the data points. The $\left[\mathrm{O}_{2}\right]_{\text {crit }}$ was estimated as the mean oxygen level corresponding to the predicted maximum ventilation rate around the peak of the lowess curve. Repeated measures ANOVA was used to test responsiveness to a repeated number of tactile stimulations under prolonged anoxia. Substrate and shelter use and activity were compared using binomial tests comparing proportions. Fish positions after interacting with the jellyfish and fish activity were compared with a Fisher's exact test.

\section{RESULTS}

\section{Responses to changes in oxygen concentration associated with DVM}

A ventilation rate of 17.5 beats $\mathrm{min}^{-1}$ was measured under fully oxygenated conditions at a water temperature of $13^{\circ} \mathrm{C}$. This increased to 26.3 beats $\mathrm{min}^{-1}$ on average during the $3 \mathrm{~h}$ of the deoxygenation period (LME; $t=7.51, \mathrm{p}<0.001, \mathrm{df}=190$; Fig. 3). The ventilation rate then dropped again during the $1.5 \mathrm{~h}$ reoxygenation period to 12.5 beats $\mathrm{min}^{-1}$ on average (LME; $t=-3.22, \mathrm{p}<0.001, \mathrm{df}=190 ;$ Fig. 3).

\section{Effects of prolonged exposure to anoxia}

The fit of the non-parametric lowess curve to the data of ventilation rate (beats $\mathrm{min}^{-1}$ ) versus $\mathrm{O}_{2}$ level (\% of air saturation) shows a maximum around $5 \%$ of air saturation. At lower oxygen concentrations a sudden drop in the number of opercula beats occurred, reaching a minimum of 0.5 beats $\min ^{-1}$ when oxygen concentration was $<0.007 \mathrm{ml} \mathrm{DO} \mathrm{l}^{-1}(0.12 \%$ air saturation; Fig. 4). $\left[\mathrm{O}_{2}\right]_{\text {crit }}$ was estimated to be $5.5 \pm 0.2 \%$ of air saturation, which corresponds well with previous measures obtained in a respirometer (Utne-Palm et al. 2010). The gobies tolerated $4.5 \mathrm{~h}$ at levels of $<0.007$ $\mathrm{ml} \mathrm{DO} \mathrm{l}^{-1}(0.12 \%$ air saturation level) without any sign of equilibrium loss. Their ventilation rate then returned to the same levels as those recorded at the start of the trials under fully oxygenated conditions (Fig. 5). 

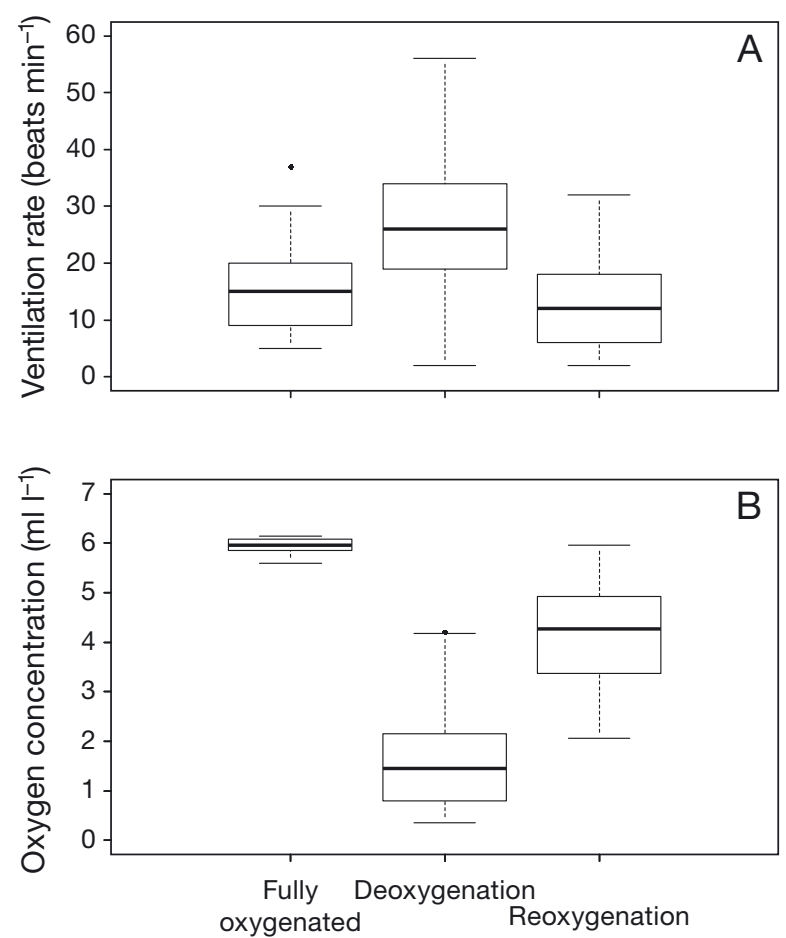

Fig. 3. Sufflogobius bibarbatus. (A) Ventilation rate (number of opercula beats $\mathrm{min}^{-1}$ ) of 35 bearded goby in fully oxygenated water at $13^{\circ} \mathrm{C}$, during $3 \mathrm{~h}$ of deoxygenation and $1.5 \mathrm{~h}$ recovery after returning to fully oxygenated seawater. The horizontal line is the median, and the bottom and top of the box the 25th and 75th percentiles, respectively. The whiskers are either maximum or $1.5 \times$ the interquartile length. Individual points outside these are defined as 'outliers'. (B) Corresponding oxygen levels for measurements shown in (A)

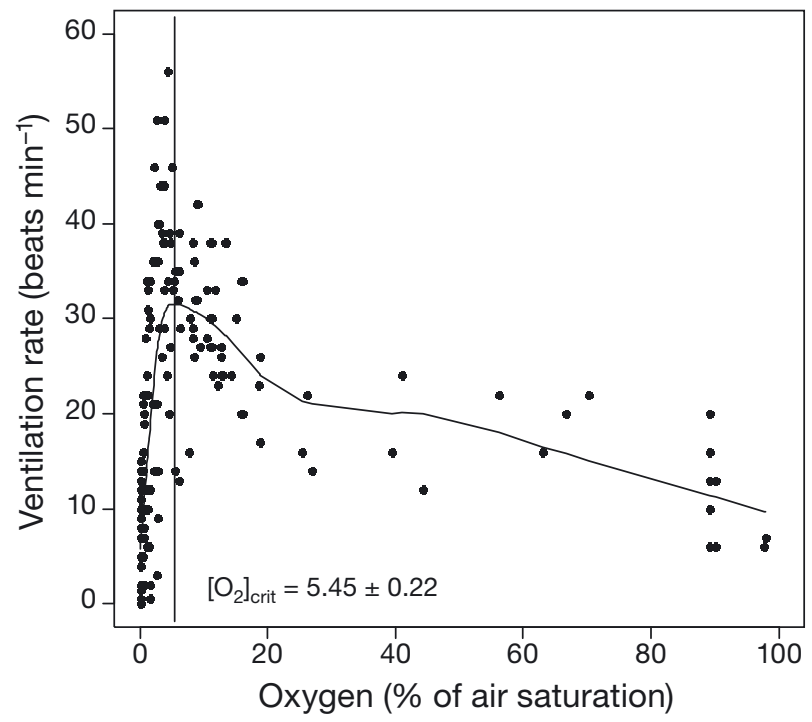

Fig. 4. Sufflogobius bibarbatus. Ventilation rate of 15 fish in response to falling seawater $\mathrm{O}_{2}$ concentration until reaching the critical oxygen concentration, $\left[\mathrm{O}_{2}\right]_{\text {crit }}$. The regression line was obtained by locally weighted scatter plot smoothing (lowess)

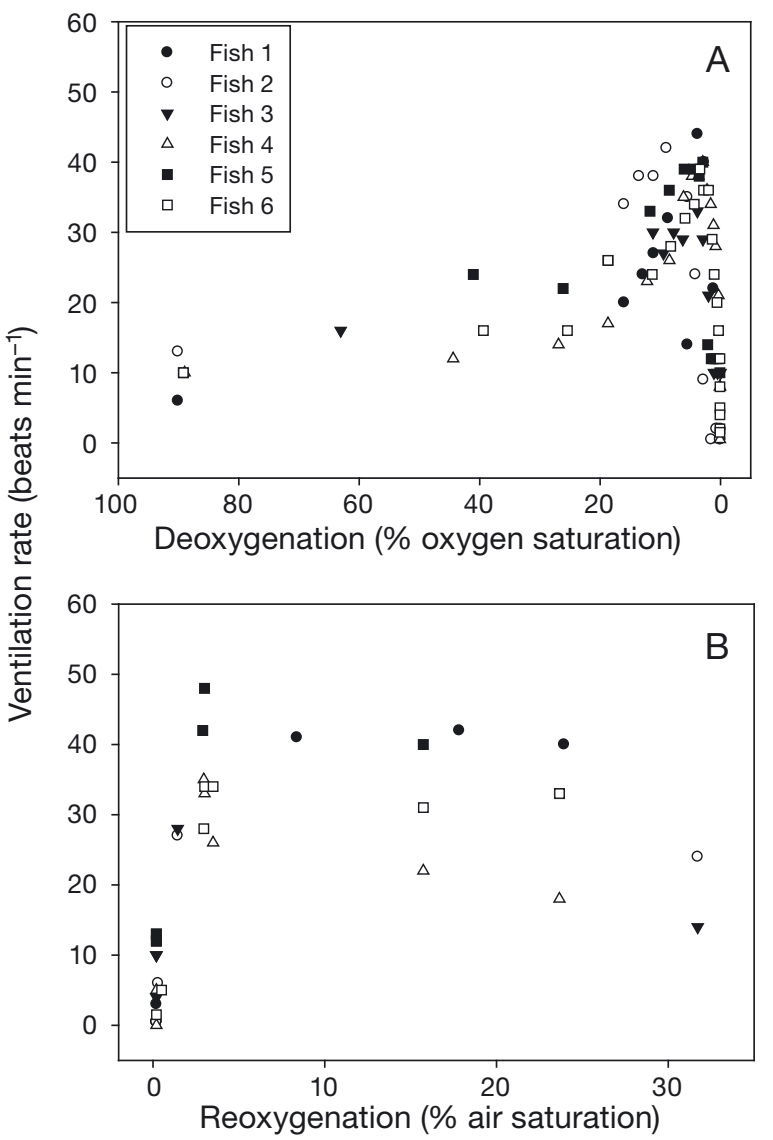

Fig. 5. Sufflogobius bibarbatus. Ventilation rates of 6 fish exposed to (A) deoxygenation followed by ca. $4.5 \mathrm{~h}$ of anoxia before they were taken through (B) reoxygenation

\section{Goby responsiveness under prolonged anoxia}

The gobies responded within $5 \mathrm{~s}$ with an escape response to tactile stimulation by a submerged lever within the aquaria. This rapid response occurred even though the fish had been exposed to anoxic water with $<0.007 \mathrm{ml} \mathrm{DO} \mathrm{l}^{-1}(<0.12 \%$ air saturation) for $4.5 \mathrm{~h}$ and hypoxic conditions below their $\left[\mathrm{O}_{2}\right]_{\text {crit }}$ for several additional hours as the tank was deoxygenated ( 4 to $5 \mathrm{~h}$ ). The time it took fish to respond increased with repeated stimulations (repeated measures ANOVA; $F_{1,13}=13.8, p=0.0026$; Fig. $6 \mathrm{~B}$ ), but the escape distance did not change significantly (repeated measures ANOVA; $F_{1,13}=3.4, p=0.088$; Fig. 6 A). Fish size had no significant effect on responsiveness.

\section{Responses to a simulated sulphide eruption}

The ventilation rate increased from 30 to 57 beats $\mathrm{min}^{-1} 30$ min after fish had been transferred from fully oxygenated water at 16 to $19^{\circ} \mathrm{C}$ to anoxic water 

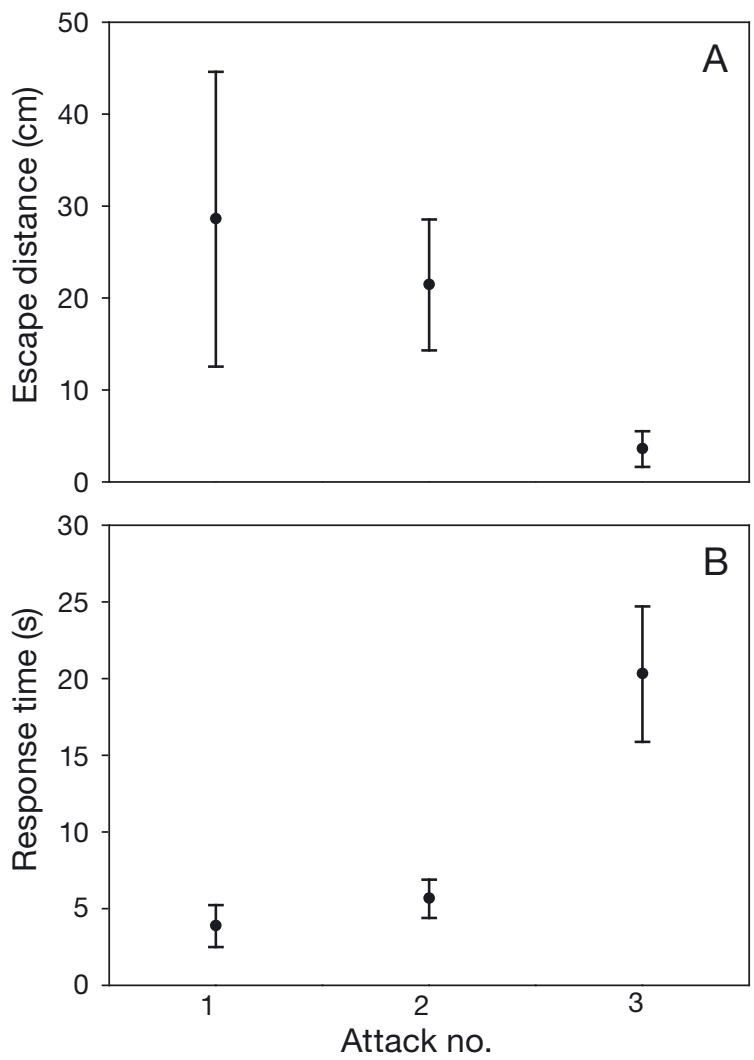

Fig. 6. Sufflogobius bibarbatus. Results from the responsiveness test of 7 fish. Attack no. 1 was initiated after ca. 6 to $8 \mathrm{~h}$ of anaerobic breathing at oxygen levels below $\left[\mathrm{O}_{2}\right]_{\text {crit }}$. Attack nos. 2 and 3 followed at 5 min intervals. (A) Change in escape distance after being triggered once, twice or 3 times. (B) Change in time to response after being triggered once, twice or 3 times. Vertical bars denote $\pm \mathrm{SE}$

$\left(<0.017 \mathrm{ml} \mathrm{DO}^{-1} ; 0.28 \%\right.$ air saturation) containing $100 \mu \mathrm{mol}$ total sulphide $(\mathrm{LME} t=13.54, \mathrm{p}<0.001, \mathrm{df}=$ 49; Fig. 7A). However, the fish recovered quickly after returning to the fully oxygenated water (LME; $t=$ $-6.39, \mathrm{p}<0.001$, df = 49; Fig. 7A). There was no significant difference in the proportion of active fish between the group in normally oxygenated conditions and the group that had been suddenly exposed to sulphide (Fisher's exact test; $\mathrm{p}=0.25$; Fig. 7B).

\section{Testing whether the mud substrate is used as a refuge}

Of the 20 fish released onto the plain plastic substrate, 15 fish moved onto the mud area (binomial test; $\left.\chi_{1}^{2}=8.1, p=0.004\right)$. Of these, 11 were observed to bury themselves within the mud while the remaining 4 stayed rested on top of the mud surface (binomial test; $\chi_{1}^{2}=4.8, \mathrm{p}=0.028$ ).
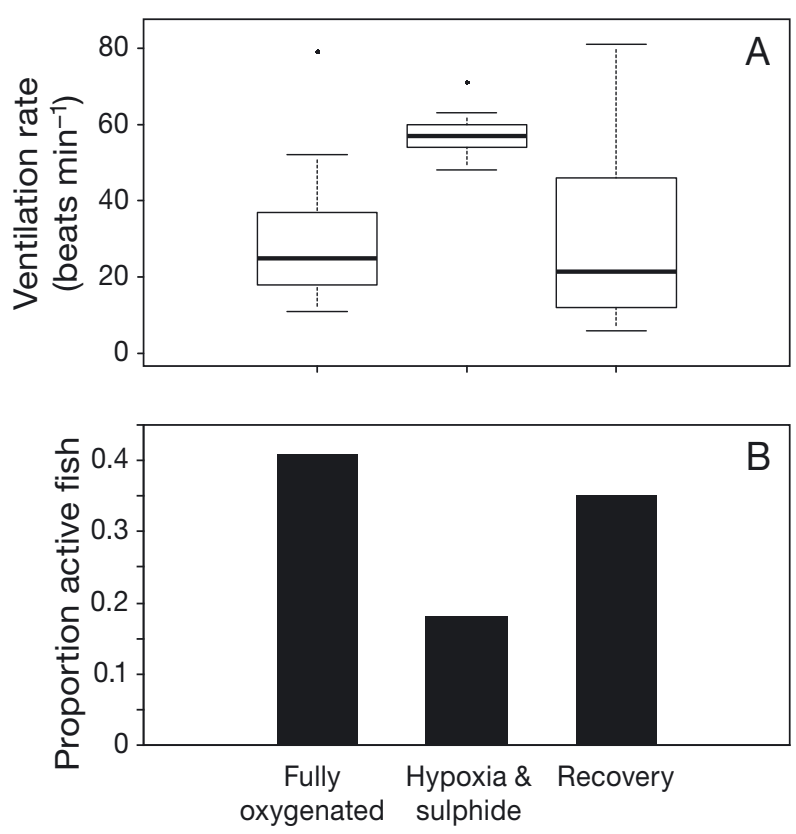

Fig. 7. Sufflogobius bibarbatus. (A) Ventilation rate (number of opercula beats $\mathrm{min}^{-1}$ ) of 17 bearded goby in fully oxygenated water at 16 to $19^{\circ} \mathrm{C}\left(6.5 \mathrm{ml}\right.$ dissolved oxygen $\left.\mathrm{l}^{-1}\right)$, after transfer to hypoxia and sulphide $(<0.01 \mathrm{ml}$ dissolved oxygen $\mathrm{I}^{-1}$ and $100 \mu \mathrm{mol} \mathrm{H}_{2} \mathrm{~S}$ ) and during recovery when returned to fully oxygenated seawater $(6.5 \mathrm{ml}$ dissolved oxygen $\mathrm{l}^{-1}$ ). The horizontal line is the median, the bottom and top of the box the 25th and 75th percentiles, respectively. The whiskers are either maximum or $1.5 \times$ the interquartile length. Individual points outside these are defined as 'outliers'. (B) Proportion of active fish under fully oxygenated, hypoxia and sulphide, and recovery conditions

\section{Goby shelter selection}

Of the 12 fish initially released, 1 at time, onto the side with the plastic substrate, 9 moved over into the section containing mud within 4 min (binomial test; $\chi_{1}^{2}=4.2, \mathrm{p}=0.041$ ), the remaining 3 fish stayed on the plastic base but none of these fish entered the PVC half-pipe shelter.

\section{Goby and juvenile horse mackerel interactions with jellyfish}

None of the horse mackerel remained on the side of the mesh with the jellyfish. The gobies, however, moved more freely between the 2 sides of the tank and 7 out of 13 gobies permanently stayed on the side with the jellyfish. These different responses were compared in a Fisher's exact test, which showed that the gobies were significantly more likely to be associated with the jellyfish compared with the horse mackerel $(p=0.005)$. 


\section{DISCUSSION}

Our results show that the bearded goby has an impressive ability to survive and exploit the extreme environment of the northern Benguela. It preferentially interacts with the anoxic and sulphidic substrate, and appears to use this as a refuge. Their response to gradual and rapid changes in oxygen showed that the fish slowed their ventilation rate to a point where they almost stopped ventilating under prolonged anoxia $\left(<0.007 \mathrm{ml} \mathrm{DO} \mathrm{l}^{-1}\right)$. Yet remarkably, the fish were able to rapidly recover both when they had been exposed to anoxia and also when they experienced high levels of sulphides. Furthermore, during anoxia when the ventilation rate was at its lowest, the fish were still alert and quickly responded to tactile stimulation. We also found considerable between-species differences in the way gobies and horse mackerel tolerated the presence of jellyfish.

It appears that the hostile nature of the inner-shelf seafloor and hypoxic waters off Namibia are forcing these adaptations. The thick mud belt supports very little benthos diversity and few other life forms are capable of surviving in this environment (Schulz et al. 1999, Levin et al. 2009). Yet this mud is home to a fish capable of withstanding extremely low oxygen conditions and sulphide conditions for prolonged periods of time. Earlier work has shown that the gobies feed on the mud and the organisms that live within it, and they also prefer to associate with mud rather than oxygenated sand (Utne-Palm et al. 2010). In the present study, we extend these observations by showing that the fish use the mud as a refuge when disturbed and prefer to interact with it rather than choosing a solid form of shelter. At the end of our observations 3 fish were placed on separate core samples of anoxic, sulphidic mud from the bottom, and, in response to a gentle prod on the tail, all 3 fish were observed to rapidly burrow between 1 and $4 \mathrm{~cm}$ into the mud, where they remained.

In order to cope in this extreme benthic environment, the gobies need to clear their oxygen debt by undertaking DVM to oxygenated water layers (UtnePalm et al. 2010), ascending in the evening and returning to the bottom by day. Acoustic measurements and CTD-station data combined with trawling have illustrated that bearded gobies spend $\sim 12 \mathrm{~h}$ on the bottom (the light hours), in areas where the $\mathrm{O}_{2}$ level was below $\left[\mathrm{O}_{2}\right]_{\text {crit }}(5.5 \pm 0.2 \%$ of air saturation; Fig. 4). To survive these conditions during daylight hours the gobies must tolerate severe hypoxia and sometimes sulphide for 10 to $12 \mathrm{~h}$. Our results indicate that this is probably possible because the fish are able to endure at least $6 \mathrm{~h}$ below $\left[\mathrm{O}_{2}\right]_{\text {crit, }}$ and at least $30 \mathrm{~min}$ with sulphide. We observed an increase in ventilation rate with decreas- ing oxygen concentration until the gobies reached their critical oxygen level, at which point a sudden decrease occurred. A depression in ventilation rate typically represents a metabolic depression. Interestingly, the goby ventilation rate during recovery did not exceed the maximum rate they show during deoxygenation (Fig. 5), which indicates that this species has a high capacity for metabolic depression under anoxic conditions. For ethical reasons, we chose to terminate these experiments after $4.5 \mathrm{~h}$ of anoxia and $30 \mathrm{~min}$ of sulphide, although the fishes' rapid recovery suggests that the experiments could have gone on for longer.

The bearded goby has an extremely low critical oxygen level $\left(\left[\mathrm{O}_{2}\right]_{\text {crit }}=5.5 \pm 0.2 \%\right.$ of air saturation $)$ compared to other species of goby (Chapman et al. 1995, Nilsson \& Östlund-Nilsson 2004, Nilsson et al. 2004, 2007), which have $\left[\mathrm{O}_{2}\right]_{\text {crit }}$ between 15 and $26 \%$ of air saturation. In comparison, these other gobies have their lowest tolerance levels between 0.4 and $6 \%$ air saturation (Nilsson et al. 2004, 2007), while the bearded goby studied here can tolerate hours of anoxia. Among other fish species known to be tolerant of hypoxic conditions are several cichlids in Lake Victoria, Africa. The lowest $\left[\mathrm{O}_{2}\right]_{\text {crit }}$ measured for these is $20 \%$ of air saturation (Chapman et al. 1995). The fact that the bearded goby tolerated $4.5 \mathrm{~h}$ in levels of $<0.007 \mathrm{ml} \mathrm{DO} \mathrm{l}^{-1}(0.12 \%$ air saturation level) below their $\left[\mathrm{O}_{2}\right]_{\text {crit }}$ shows that they have an extremely high anaerobic capacity. Other coral-dwelling goby species from Australia have been shown to stay in shallow hypoxic coral areas at low tide to avoid predation rather than moving into the deeper open areas (Nilsson \& Östlund-Nilsson 2004, Nilsson et al. 2004, 2007). Other studies of e.g. Pacific gobies have also shown that some of these species are tolerant of water with low oxygen concentrations (Congleton 1974). To our knowledge the bearded goby seems to be one of the most hypoxia-tolerant marine teleost species ever studied. Whether their tolerance varies with variations in hypoxic conditions on the shelf is not yet resolved, but pilot studies on genetic structuring indicate genetic heterogeneity in the population (Gunawickrama et al. 2010). It would be intriguing to know if there are subpopulations that vary in their adaptation to hypoxia and anoxia.

The bearded goby was also capable of tolerating abrupt drops in DO in combination with sulphide, a situation that mimics sulphur eruptions that occur frequently in the northern Benguela. The bearded goby responded with an immediate increase in ventilation rate, but unlike other fish exposed to sulphide eruptions, the gobies survived and recovered rapidly after returning to fully oxygenated waters. In the northern Benguela there are frequent events with diffusion and ebullition of hydrogen sulphide gas from 
the sediments (Weeks et al. 2004), and it has been known for more than $100 \mathrm{yr}$ that this phenomenon has been involved in mass killing of other fish and invertebrates (Copenhagen 1934, Rogers \& Bremner 1991).

A comparison between the goby and a common pelagic species, the horse mackerel, revealed clear differences in the response of these 2 species to the presence of jellyfish. The horse mackerel showed a strong aversion to being in close proximity with the jellyfish, whereas the gobies appeared to be indifferent. During the evening, gobies migrate up to shallower waters of the pelagic where multiple fish predators are present. The first oxygenated waters that they will meet are dominated by jellyfish (Lynam et al. 2006). Our results indicate that this is a safe area for the gobies because typical predatory species, such as the horse mackerel, avoid association with jellyfish. In fact, Utne-Palm et al. (2010) demonstrated that jellyfish is part of the goby diet, thus returning previously believed dead-end products back to the ecosystem. While it is not yet clear whether the gobies scavenge on dead jellyfish on the bottom, or whether they feed on them in the pelagic layer, interactions with the jellyfish through the night would certainly provide them with an opportunity to consume jellyfish.

Bearded gobies performed a fast escape response when prodded after $4.5 \mathrm{~h}$ of anoxia $\left(<0.007 \mathrm{ml} \mathrm{DO} \mathrm{l}^{-1}\right)$. Their time lag before responding to tactile stimulation increased significantly with the number of attacks they experienced, but response distance did not change significantly. Thus, whether these observations are an effect of the fish becoming conditioned to the stimuli or a result of it running out of energy could not be determined from the data. Interestingly though, this experiment shows that the gobies are able to pay attention to predation risk even during prolonged anaerobic respiration. Potential predators such as seals, penguins and seabirds will be able to dive down and capture gobies on the bottom. Although not quantified, visual observations indicated that the area around the brain and gills became more visible and red during metabolic depression. This may possibly be caused by an increase in blood flow to the brain at the cost of reduced flow to other organs. Maintaining some kind of awareness during their time on the hypoxic seabed is probably a necessity for the goby to avoid possible predation and to recognise when it is time for their ascent to the more oxygenated, pelagic waters in the evening.

Taken together these different adaptations highlight just how well adapted the bearded goby is to the northern Benguela environment. These fish can withstand extremely low oxygen concentrations for long periods of time, and they are barely affected by sulphide levels that cause massive mortalities of other marine species during eruption events. These fish also seem to have developed unique predator evasion strategies; they seek shelter in hypoxic mud or choose to associate with jellyfish, both environments that their predators tend to avoid. Elsewhere, gobies have successfully exploited shallow water estuaries or tide-pools where there are great fluctuations in salinity, temperature and oxygen levels. It is therefore not surprising that it is a goby species that has succeeded in the harsh Benguela ecosystem.

Acknowledgements. We thank the Norwegian and South African Research Councils for funding of a workshop held at Geilo in April 2010, and which allowed time for writing up these results. Further, we thank our mentor S. Sundby and our colleague J. O. Kraakstad at the Institute of Marine Research (IMR) for their support and for sharing their knowledge on the Benguela with us. The NANSEN program at UiB and IMR, FAO and BENEFIT are acknowledged for their valuable support in terms of ship time on the RVs 'Dr. Fridtjof Nansen' and 'G.O. Sars'. We are most grateful to F. Midtøy for designing the experimental set-up and providing valuable support. We thank K. Peard, C. Chikwiliwa, P. Ellitson and J. Gei-Khaub for technical assistance, the crew on RVs 'Dr. Fridtjof Nansen' and 'G.O. Sars' for all their assistance and E. Holm and S. Kolbeinson for help with figure drawing. This project was funded by the South African National Research Foundation, the Norwegian Research Council, the University of Bergen, National Marine Information and Research Centre (NatMIRC) Namibia, and ship time by BENEFIT, FAO and IMR.

\section{LITERATURE CITED}

Beamish FWH (1964) Seasonal changes in the standard rate of oxygen consumption in fishes. Can J Zool 42:189-194

> Benton MJ, Twitchett RJ (2003) How to kill (almost) all life: the end-Permian mass extinction event. Trends Ecol Evol 18:358-365

Berner RA (2005) The carbon and sulfur cycles and atmospheric oxygen from middle Permian to middle Triassic. Geochim Cosmochim Acta 69:3211-3217

Brüchert V, Currie AB, Peard KP (2009) Hydrogen sulphide and methane emissions on the central Namibian shelf. Prog Oceanogr 83:169-179

> Chapman LJ, Kaufman LS, Chapman CA, McKenzie FE (1995) Hypoxia tolerance in 12 species of East-African cichlids - potential for low-oxygen refugia in Lake Victoria. Conserv Biol 9:1274-1287

> Cline DL (1969) Spectrophotometric determination of hydrogen sulfide in natural waters. Limnol Oceanogr 14:454-458

> Congleton JL (1974) The respiratory response of asphyxia of Typhlogobius californiensis (Teleostei: Gobiidae) and some related gobies. Biol Bull (Woods Hole) 146:186-205

Copenhagen WJ (1934) Occurrence of sulphides in certain areas of the sea bottom on the South African coast. Fish Mar Biol Surv Div, Dep Commerce and Industries, Union South Africa, Invest Rep 3. Union of South Africa, Government Printers, Pretoria

Crawford RJM, Shannon LV, Pollock DE (1987) The Benguela ecosystem. Part IV: The major fish and invertebrate resources. Oceanogr Mar Biol Annu Rev 25:353-505

Crawley MJ (2007) The R book. R: a language and environment for statistical computing. R Foundation for Statistical Computing, Vienna 
Grice K, Cao C, Love GD, Böttcher ME and others (2005) Photic zone euxinia during the Permian-Triassic superanoxic event. Science 307:706-709

Gunawickrama KBS, De Silva PMCS, Johansen T, Salvanes AGV, Nævdal G (2010) Preliminary evidence for genetic heterogeneity of the goby (Sufflogobius bibarbatus) in the Benguela ecosystem. J Appl Ichthyol 26:110-112

Lane N (2007) Mass extinctions: reading the book of death. Nature 448:122-125

Lavik G, Stührmann T, Brüchert V, Van der Plas A and others (2009) Detoxification of sulphidic African shelf waters by blooming chemolithotrophs. Nature 457:581-584

Levin LA, Ekau W, Gooday AJ, Jorissen F and others (2009) Effects of natural and human-induced hypoxia on coastal benthos. Biogeosciences Discuss 6:3563-3654

Lynam CP, Gibbons MJ, Axelsen BE, Sparks CAJ, Coetzee J, Heywood BJ, Brierley AS (2006) Jellyfish overtake fish in a heavily fished ecosystem. Curr Biol 16:R492-R493

Nilsson GE, Östlund-Nilsson S (2004) Hypoxia in paradise: widespread hypoxia tolerance in coral reef. Proc $\mathrm{R}$ Soc Lond 271:S30-S33

Nilsson GE, Hobbs JP, Munday PL, Östlund-Nilsson S (2004) Coward or brave heart: extreme habitat fidelity through hypoxia tolerance in a coral-dwelling goby. J Exp Biol 207:33-39

Nilsson GE, Hobbs JP, Östlund-Nilsson S, Munday PL (2007) Capacity for water and air breathing correlates with habitat preference in coral-dwelling fishes. Coral Reefs 26: 241-248

Editorial responsibility: Roger Hughes,

Bangor, UK
Rogers J, Bremner JM (1991) The Benguela ecosystem: marine-geological aspects. Oceanogr Mar Biol Annu Rev 29:1-85

Schulz HN, Brinkhoff T, Ferdelmam TG, Hernández Mariné M, Teske A, Jørgensen BB (1999) Dense populations of a giant sulfur bacterium in Namibian shelf sediment. Science 284:493-495

Utne-Palm AC, Salvanes AGV, Currie B, Kaartvedt S and others (2010) Tropic structure and community stability in an overfished ecosystem. Science 329:333-336

van der Lingen CD, Shannon LJ, Cury P, Kreiner A, Moloney CL, Roux JP, Vaz-Velho F (2006) Resource and ecosystem variability, including regime shifts in the Benguela Current System In: Shannon LV, Hempel G, Malanotte-Rizzoli G, Moloney CL, Woods J (eds) Benguela: predicting a large marine ecosystem. Large Marine Ecosystems 14, Elsevier, Amsterdam, p 147-184

- Weeks SJ, Currie B, Bakun A (2002) Massive emissions of toxic gas in the Atlantic. Nature 415:493-494

> Weeks SJ, Currie B, Bakun A, Peard KR (2004) Hydrogen sulphide eruptions in the Atlantic Ocean off southern Africa: implications of new view based on SeaWIFS satellite imagery. Deep-Sea Res 51:153-172

Weiss R (1970) The solubility of nitrogen, oxygen and argon in water and seawater. Deep-Sea Res 17:721-735

Zhang J, Gilbert D, Gooday AJ, Levin L and others (2010) Natural and human-induced hypoxia and consequences for coastal areas: synthesis and future development. Biogeosciences 7:1443-1467

Submitted: October 14, 2010; Accepted: December 14, 2010 Proofs received from author(s): February 28, 2011 